\title{
Worldview Differences Between College Students and Graduate Counseling Trainees
}

\section{WEI-CHENG MAU DONALD B. POPE-DAVIS}

\begin{abstract}
The purpose of this study was to examine whether graduate students in counseling $(\mathrm{n}=95)$ have different worldviews than undergraduate students $(\mathrm{n}=177)$ who might be potential clients. Students in both groups completed the Scale to Assess World Views (Ibrahim E Kahn, 1987). Results indicated that undergraduate students' worldviews were significantly different from graduate counseling students'. In comparison, undergraduates were more likely than graduate counseling students to focus on the past, to perceive human nature as evil, human relationships as linearhierarchical and collateral-mutual, and nature as powerful. Graduate counseling trainees, on average, were more likely than undergraduates to perceive human nature as good. Men were more likely than women to perceive human nature as evil, human relationships as linear-hierarchical and individualistic, and nature as controllable. Women, in contrast, preferred the being-in-becoming modality. Implications and limited generalizability of these findings for counseling are discussed.
\end{abstract}

Worldviews have been seen by many (Carter, 1991; Ibrahim, 1985, 1991; Ivey, Ivey, \& Simek-Downing, 1987; Pedersen, 1988; Sue, 1978a; Sue \& Sue, $1990)$ as an important variable that has contributed to counseling effectiveness. Counselors who have worldviews that are different from their clients' and who are unaware of these differences are more likely to attribute negative traits to theirclients (Sue \& Sue, 1990). A lack of understanding regarding counselor and client worldviews can result in frustration and anxiety for both individuals. Ivey et al. (1987) suggested that being aware of one's own worldviews and how those views may be different from the clients' is essential if appropriate counseling is to take place. An awareness of 
worldviews can help the counselor develop goals and objectives that are consistent with the value orientation of the client (Ibrahim, 1991).

Worldviews refer to the beliefs, values, and assumptions that mediate communication, relationships, modes of problem solving, decision making, and life-styles of clients (Ibrahim \& Schroeder, 1990). As a result, each person can have worldviews that might be influenced by their religious beliefs, education, social class, age, gender, ethnicity, and culture. Without an understanding of worldviews as a mediating variable, knowledge of cultures and culture-specific techniques can not be appropriately applied, nor can applications of theory and research take place (Ibrahim, 1991).

One of the most useful frameworks for understanding differences among individuals and groups is the Kluckhohn and Strodtbeck (1961) worldview model. From an existential perspective, they constructed a worldview model based on five universal problems encountered by all people. These universal problems are addressed by five existential questions: (a) What is the character of human nature? (b) What is a human being's relationship to other humans? (c) What is the relation of human beings to nature and the supernatural? (d) What is the temporal focus of human life? (e) What is the modality of human activity?

Kluckhohn and Strodtbeck's (1961) model has been widely used in explaining worldview differences among various racial and ethnic groups (Carter, 1990, 1991; Chandler, 1979; Papajohn \& Spiegel, 1975; Sodowsky, Maguire, Johnson, Ngumba, \& Kohles, in press; Trimble, 1976). In general, these studies have found that White middle-class Americans differ in worldviews significantly from Black Americans (Carter, 1990), Native Americans (Trimble, 1976), Mexican Americans (Chandler, 1979), international students (Sodowsky et al., in press), and immigrants (Papajohn \& Spiegel, 1975). Carter (1991) in his recent review of the model noted that worldview differences seem to exist within social classes (Lengermann, 1972), gender (Caudill \& Scarr, 1962), and generations (Carter \& Parks, 1990).

Although researchers have acknowledged the potentially adverse effects of not considering worldviews as part of the life experiences of clients (Ibrahim, 1985; Pedersen, 1988; Sue, 1978b), very few studies have investigated the worldviews of counselors and how they might be different from clients' worldviews. The implication is that graduate students who are pursuing a career in a helping profession, and who are trained by various sets of counseling philosophies may develop worldviews that are different from those of their potential clients. The purpose of this study, therefore, was to examine whether students who are now in counseling training might have different worldviews than do students who might be potential clients. Studies (Altmaier \& Rapaport, 1984; Cook et al., 1984) have shown that a high percentage of undergraduate students indicated they need counseling help for various reasons. Related studies (Berdie \& Stein, 1966) have also reported that counseled and noncounseled undergraduates were not sig- 
nificantly different in terms of adjustment, achievement, or occupational interests. Undergraduate students, therefore, were considered as potential clients in this study. Since gender, age, and education are also likely to influence worldviews (Ibrahim, 1985), these variables were included in analyzing worldview differences of clients and counselors.

\section{METHOD}

\section{Participants}

Two groups representing potential student clients and counselors at a major midwestern university were asked to participate in this investigation. Those defined as potential clients were students enrolled in undergraduate introductory statistics or career education courses. Counselors were counseling students enrolled in counselor education and counseling psychology graduate courses. A sample of 274 students agreed to participate and anonymously completed the questionnaire. Of the 274 students, two students inappropriately completed the questionnaire. Thus, the final sample consisted of 177 student clients (76 men and 101 women) and 95 counseling trainees ( 20 men and 75 women), for a total of 272 participants.

The mean age of the student client group $(N=177)$ was 20.6 with a standard deviation of 2.6. The majority of students in this group were second-year undergraduate students. Approximately $92 \%$ of these participants were White, and $8 \%$ were minority students. The mean age of the potential counselor group $(N=95)$ was 34 with a standard deviation of 8.6. In this group $68 \%$ of the participants were master's students, and $32 \%$ were doctoral students. Approximately $94 \%$ were White, and $6 \%$ were minority students.

\section{Instrument}

The Scale to Assess World Views (SAWV) constructed by Ibrahim and Kahn (1987) was used to assess worldviews. The SAWV is a 45-item 5-point Likert-type scale of self-descriptive statements (e.g., "I feel quite powerless when faced with the forces of nature"). The SAWV has five categories, with three subdivisions within each category, offering three possible alternatives for each question. The five categories and their subdivisions are: (a) human nature-good, a combination of good and evil, and evil; (b) relationshipslinear-hierarchial, collateral-mutual, and individualistic; (c) nature-subjugating and controlling nature, harmony with nature, and power of nature; (d) time orientation - past, present, and future; and (e) activity orientation- 
being, being-in-becoming, and doing. The scale, therefore, has 15 subdivisions (see Table 1 for the full names of the categories and subdivisions). There are 9 items in each category, totaling 45 items for the scale. Ibrahim and Kahn (1987) reported a coefficient alpha reliability of .98 for the scale. We believe, however, stability of the measured constructs is considered as more relevant than homogeneity. Therefore, before conducting the study, estimates of the test-retest reliability of the 15 subdivision scales were obtained by administering the scales twice to the students in the introductory statistics class over a 3-week period. A total of 53 undergraduate students participated in both assessments. The test-retest estimates found for the 15 subscales ranged from .27 to .82 with a mean of .56 . Sodowsky et al. (in press) also estimated test-retest reliability ( 3 months) based on a group of 30 master's and doctoral-level counseling psychology students. Their results indicated a stability index of .67 for the SAWV scale. Based on these findings, the measurement was considered acceptable for this investigation.

Parents' Education. Parents' educational backgrounds were used as an independent variable. A checklist containing seven educational levels, ranging from "completed 8th grade or less" to "graduated from graduate school or professional school" was constructed. Participants were provided with two separate checklists, one of their male guardian or parent and one for their female guardian or parent. Parent education was then categorized into an upper and lower level. If both of the student's guardians or parents had graduated from high school or at least one guardian or parent had a higher degree, an upper level was assigned. Otherwise, a lower level was assigned.

\section{RESULTS}

\section{Descriptive Statistics}

Although the major purpose of this study was to examine the worldviews of client and counselor, an overview of the highest subscale score means for each group and gender may be interesting to the reader. Adjusted means and standard deviations for the SAWV subscales by student group and sex are presented in Table 1. A high mean score indicates high endorsement of items representing a specific view. For example, the student client group obtained the highest mean score on the subscales of "Good and evil" in human nature, "Collateral-mutual" human relations, "Power of nature," "Present" time orientation, and "Being-in-becoming" activity orientation. Additional observations on counselor, male, and female groups can also be found in Table 1. 
TABLE 1

Adjusted Means, Standard Deviations, and F Test of Subdivisions in the Five Worldviews

\begin{tabular}{|c|c|c|c|c|c|c|c|c|c|c|}
\hline \multirow[b]{2}{*}{ Categories } & \multicolumn{2}{|c|}{$\begin{array}{c}\text { Client } \\
(N=177)\end{array}$} & \multicolumn{2}{|c|}{$\begin{array}{c}\text { Counselor } \\
\text { (N=95) }\end{array}$} & \multirow{2}{*}{$\begin{array}{c}\text { Client/ } \\
\text { Counselor } \\
F(1,271)\end{array}$} & \multicolumn{2}{|c|}{$\begin{array}{c}\text { Male } \\
(N=96)\end{array}$} & \multicolumn{2}{|c|}{$\begin{array}{l}\text { Female } \\
(N=176)\end{array}$} & \multirow{2}{*}{$\begin{array}{c}\text { Male/ } \\
\text { Female } \\
F(1,271)\end{array}$} \\
\hline & $M$ & SD & $M$ & SD & & $\boldsymbol{M}$ & SD & $M$ & SD & \\
\hline $\begin{array}{l}\text { Human Nature } \\
\text { Evil } \\
\text { Good and evil } \\
\text { Good }\end{array}$ & $\begin{array}{r}8.24 \\
10.94 \\
10.60\end{array}$ & $\begin{array}{l}1.89 \\
1.65 \\
1.42\end{array}$ & $\begin{array}{r}7.46 \\
10.31 \\
11.30\end{array}$ & $\begin{array}{l}1.75 \\
1.86 \\
1.49\end{array}$ & $\begin{array}{l}4.44^{\star} \\
3.36 \\
5.97^{\star}\end{array}$ & $\begin{array}{r}8.34 \\
10.88 \\
10.68\end{array}$ & $\begin{array}{l}2.12 \\
1.95 \\
1.43\end{array}$ & $\begin{array}{r}7.85 \\
10.76 \\
10.98\end{array}$ & $\begin{array}{l}1.74 \\
1.70 \\
1.46\end{array}$ & $\begin{array}{l}4.30^{\star} \\
0.35 \\
2.60\end{array}$ \\
\hline $\begin{array}{l}\text { Human Relations } \\
\text { Linear-hierarchical } \\
\text { Collateral-mutual } \\
\text { Individualistic }\end{array}$ & $\begin{array}{l}6.08 \\
9.38 \\
7.04\end{array}$ & $\begin{array}{l}2.25 \\
1.94 \\
1.85\end{array}$ & $\begin{array}{l}4.83 \\
8.49 \\
6.46\end{array}$ & $\begin{array}{l}1.81 \\
1.83 \\
1.74\end{array}$ & $\begin{array}{l}8.72^{\star \star} \\
5.57^{\star} \\
2.52\end{array}$ & $\begin{array}{l}6.70 \\
9.25 \\
7.62\end{array}$ & $\begin{array}{l}2.50 \\
1.79 \\
1.94\end{array}$ & $\begin{array}{l}5.14 \\
9.15 \\
6.41\end{array}$ & $\begin{array}{l}1.77 \\
2.14 \\
1.60\end{array}$ & $\begin{array}{c}36.55^{\star \star \star} \\
0.16 \\
29.89^{\star \star \star}\end{array}$ \\
\hline $\begin{array}{l}\text { Relations to Nature } \\
\text { Subjugating nature } \\
\text { Harmony with nature } \\
\text { Power of nature }\end{array}$ & $\begin{array}{r}7.13 \\
10.78 \\
11.04\end{array}$ & $\begin{array}{l}1.76 \\
1.89 \\
1.88\end{array}$ & $\begin{array}{r}7.07 \\
10.88 \\
10.06\end{array}$ & $\begin{array}{l}1.84 \\
1.92 \\
1.78\end{array}$ & $\begin{array}{l}0.03 \\
0.07 \\
7.16^{\star \star}\end{array}$ & $\begin{array}{r}7.41 \\
10.79 \\
10.75\end{array}$ & $\begin{array}{l}1.80 \\
2.03 \\
2.01\end{array}$ & $\begin{array}{r}6.95 \\
10.74 \\
10.66\end{array}$ & $\begin{array}{l}1.76 \\
1.85 \\
1.82\end{array}$ & $\begin{array}{l}3.93^{\star} \\
0.04 \\
0.12\end{array}$ \\
\hline $\begin{array}{l}\text { Time Orientation } \\
\text { Past } \\
\text { Present } \\
\text { Future }\end{array}$ & $\begin{array}{l}7.70 \\
8.51 \\
7.97\end{array}$ & $\begin{array}{l}1.74 \\
2.59 \\
1.84\end{array}$ & $\begin{array}{l}6.73 \\
8.02 \\
8.11\end{array}$ & $\begin{array}{l}1.59 \\
2.32 \\
1.92\end{array}$ & $\begin{array}{l}8.06^{\star \star} \\
0.96 \\
0.15\end{array}$ & $\begin{array}{l}7.62 \\
8.51 \\
8.16\end{array}$ & $\begin{array}{l}1.75 \\
2.67 \\
1.88\end{array}$ & $\begin{array}{l}7.23 \\
8.27 \\
8.08\end{array}$ & $\begin{array}{l}1.72 \\
2.41 \\
1.86\end{array}$ & $\begin{array}{l}3.20 \\
0.58 \\
0.10\end{array}$ \\
\hline $\begin{array}{l}\text { Activity Orientation } \\
\text { Being } \\
\text { Being-in-becoming } \\
\text { Doing }\end{array}$ & $\begin{array}{r}9.73 \\
10.85 \\
10.31\end{array}$ & $\begin{array}{l}1.59 \\
1.53 \\
1.70\end{array}$ & $\begin{array}{r}9.74 \\
11.18 \\
10.05\end{array}$ & $\begin{array}{l}1.88 \\
1.47 \\
1.86\end{array}$ & $\begin{array}{l}0.00 \\
1.21 \\
0.55\end{array}$ & $\begin{array}{r}9.81 \\
10.51 \\
10.45\end{array}$ & $\begin{array}{l}1.58 \\
1.52 \\
1.85\end{array}$ & $\begin{array}{r}9.63 \\
11.23 \\
10.28\end{array}$ & $\begin{array}{l}1.76 \\
1.44 \\
1.78\end{array}$ & $\begin{array}{c}0.66 \\
14.59^{\star \star \star} \\
0.57\end{array}$ \\
\hline
\end{tabular}

Note. The potential score range for each scale is from 3 to 12 .

${ }^{*} p<.05 .{ }^{* *} p<.01{ }^{* * *} p<.001$. 
To examine differences in worldviews between undergraduate and counseling students, a 2 (student group) $\times 2$ (sex) $\times 2$ (education) multivariate analysis of covariance (MANCOVA) was conducted. The covariate analyses were conducted because age was found to be correlated with the worldview scales (significant at .01 level with eight subscales) and was significantly different between groups $(t=19.88 ; p<.001)$. The analysis of covariance was expected to result in a more precise estimate of error variance, and thereby produce a relatively equitable comparison of differences between groups. It should be noted, however, that the use of covariance analysis without random assignment of samples may cause an inaccurate estimation of parameters. Since the covariate (age) is fairly free of measurement error, the bias estimation of the parameters is less of a concern. The covariance analysis can be used with caution in circumstances where random assignment is impractical or is difficult to obtain (Pedhazur, 1984).

A significant MANCOVA main effect was found for groups, $F(15,249)=$ $1.75, p=.042$, and gender, $F(15,249)=3.03, p<.001$. Educational attainment was not significant, $F(15,249)=.74, p=.74$. No other significant main or interaction effects were observed. Follow-up ANCOVAs for the individual scales revealed significant group main effects for six scales: Human nature is evil, Human nature is good, Human relationships are linear-hierarchial, Human relationships are collateral-mutual, Nature is powerful, and Focusing on the past. Means, standard deviations, and $F$ tests are presented in Table 1.

Clients, on the average, scored significantly higher than counselors on Human Nature (Evil), Human Relation (Linear-hierarchial), Human Relations (Collateral-mutual), Relations to Nature (Power of nature), and Time Orientation (Past) subscales. Counselors, on the other hand, scored significantly higher than clients did on Human Nature (Good) subscale.

Follow-up ANCOVAs for the individual scales also revealed significant gender effects for five scales: Human nature is evil, Human Relationships are linear-hierarchial, Human relationships are individualistic, Nature should be subjugated and controlled, and "Being-in-becoming" or preference for goal-directed activities leading to development of self.

Men, on the average, scored significantly higher than women in Human Nature (Evil), Human Relations (Linear-hierarchial), Human Relations (Individualistic), and Relations to nature (Subjugating nature) subscales. Women, on the other hand, scored significantly higher on the Activity Orientation (Being-in-becoming) subscale.

Age as a covariate variable seems to have accounted for a great deal of variance in the criterion measures. A total of 8 of 15 subdivisions were significantly related to age: Human nature is evil $F(1,271)=15.71, p<.001$; Human nature is a combination of good and evil $F(1,271)=18.86, p<.001$; 
Human relationships are hierarchial $F(1,271)=19.39, p<.001$; Human relationships are collateral-mutual $F(1,271)=35.60, p<.001$; The powerfulness of nature $F(1,271)=6.64, p<.01$; Past time orientation $F(1,271)=$ 9.96, $p<.01$; Future time orientation $F(1,271)=5.66, p<.05$; and Doing Activity modality $F(1,271)=24.42, p<.001$.

\section{DISCUSSION}

The findings from this study generally support speculative assumptions made by many theorists and practitioners (Ibrahim, 1985; Ivey et al., 1987; Sue, 1978a; Sue \& Sue, 1990), in that clients and counselors hold different worldviews. The results also suggest that men differ from women in worldviews. The categorization of parents' educational levels did not result in significant differences in students' worldviews.

The differences in worldviews between counselors in training and undergraduate students may be due to counselors' having been trained with particular sets of worldviews or theories. Many of the current counseling theories have been constructed based on the cultural values of middle-class Caucasians. Thus, counseling students who study these counseling theories are likely to endorse a particular set of worldviews (Pedersen, 1988). It is also possible that counseling students who pursue helping careers may hold a particular set of worldviews or values that are different from others'. The worldviews they originally held may have influenced them to enter counseling careers. Further research that compares counseling students in different stages of their professional training (e.g., before, during, and after training) should be done to examine this factor.

Another reason that might account for the differences is that the counseling students and undergraduate students in this study were quite different in age-the counseling students were considerably older than the student clients group. Given the fast-changing social systems, economic conditions, and the advancement of modern technology, younger individuals are more likely to possess values that are different from those of older individuals. Because age was statistically controlled in analyzing worldview differences, other factors may also have accounted for the group differences.

It is possible that differences in worldviews may be related to developmental differences between counselors and clients. This would imply that worldview constructs are associated with developmental levels that could be measured on a continuous scale. Thus, an individual would progress through hierarchical stages in maturity of worldviews. We suggest that a comparison of worldviews in absolute terms is very difficult to make. Nonetheless, as Sue (1978a) has suggested, counselors need to understand the basis of worldview, to accept the possible legitimacy of others, and to stress the positives that each view offers.

Since this is an exploratory instead of explanatory study, our discussion of worldview differences is contemplative and tentative. Further research 
may be able to establish a causal model to explain the worldview differences of counselors and clients.

Our study is limited in scope for a number of reasons. First, undergraduate students selected for this study may not resemble clients in general. It may also be true that our counseling students may not be representative of all students in training. It is necessary to confine generalizations only to populations that resemble our sample groups. Moreover, as was mentioned earlier, our samples were not random samples. Extraneous factors other than age, gender, and educational background may have confounded the results. Further research comparing random clinical and student samples may be able to provide data for making greater generalizations.

Second, the instrument used in this study was newly constructed by Ibrahim and Kahn (1987). They factor analyzed the underlying construct of the scale and found five multidimensional constructs. The validity and reliability of the scale have not been fully reported. The stability of the scale estimated for this study was moderate (the average test-retest reliability for the 15 subscales was .56). The original proposed subscale used in this study, rather than the five dimensions, may not have made best use of the psychometric property of the scale.

Third, we dichotomized the parents' educational background into upper and lower groups in our factorial study. This dichotomization may be lacking in precision for detecting the differences. Further research using analyses that employ a more precise approach (e.g., regression analyses) may reduce the error.

Given the findings, we suggest that counseling practitioners may wish to begin by examining their values and perceptions and what effect they have on clients of different worldviews. Several models and frameworks have been developed to enhance counselor awareness (Pedersen, 1988) and to accommodate clients with different cultural backgrounds and value orientations (Atkinson, Morten, \& Sue, 1989; Ibrahim, 1991; Ivey et al., 1987; Sue $\&$ Sue, 1990; also see special issue of Journal of Counseling $\mathcal{E}$ Development, September/October, 1991). Ivey (1977) described effective counselors as being able to share the worldviews of their clients, and to help the clients integrate aspects of worldviews that will maximize the clients' effectiveness and psychological well-being. We strongly urge that counseling professionals adopt counseling models, or develop their own theoretical framework and counseling skills, appropriate for clients of different worldviews.

\section{REFERENCES}

Altmaier, E. M., \& Rapaport, R. J. (1984). An examination of student use of a counseling service. Journal of College Student Personnel, 25, 453-458. 
Atkinson, D. R., Morten, G., \& Sue, S. W. (1989). Counseling American minorities: A cross-cultural perspective (3rd ed.). Dubuque, IA: William C. Brown.

Berdie, R. F., \& Stein, J. (1966). A comparison of new university students who do and do not seek counseling. Journal of Counseling Psychology, 13, 310-317.

Carter, R. T. (1990). Cultural values differences between African Americans and White Americans. Journal of College Student Development, 31, 71-79.

Carter, R. T. (1991). Cultural values: A review of empirical research and implications for counseling. Journal of Counseling \& Development, 70, 165-173.

Carter, R. T., \& Parks, E. E. (1990). White ethnic group membership and cultural value preferences. Unpublished manuscript.

Caudill, W., \& Scarr, H. A. (1962). Japanese value orientation and cultural change. Ethnology, 1, 53-91.

Chandler, C. R. (1979). Traditionalism in a modern setting: A comparison of Anglo and MexicanAmerican value orientations. Human Organization, 38, 153-159.

Cook, E. P., Park, W., Williams, G. T., Webb, M., Nicholson, B., Schneider, D., \& Bassman, S. (1984). Students' perception of personal problems, appropriate help sources, and general attitudes about counseling. Journal of College Student Personnel, 25, 139-145.

Ibrahim, F. A. (1985). Effective cross-cultural counseling and psychotherapy: A framework. The Counseling Psychologist, 13, 625-638.

Ibrahim, F. A. (1991). Contribution of cultural worldview to generic counseling and development. Journal of Counseling E Development, 70, 13-19.

Ibrahim, F. A., \& Kahn, H. (1987). Assessment of world views. Psychological Reports, 60, 163-176.

Ibrahim, F. A., \& Schroeder, D. G. (1990). Cross-cultural counseling: A developmental, psychoeducational intervention. Journal of Comparative Family Studies, 21, 193-205.

Ivey, A. E. (1977). Toward a definition of the culturally effective counselor. The Personnel and Guidance Journal, 55, 296-302.

Ivey, A. E., Ivey, M. B., \& Simek-Downing, L. (1987). Counseling and psychotherapy: Integrating skills, theory, and practice. Englewood Cliffs, NJ: Prentice-Hall.

Kluckhohn, F. R., \& Strodtbeck, F. L. (1961). Variation in value orientations. Evanston, IL: Row, Patterson, \& Co.

Lengermann, P. M. (1972). The debate on the structure and content of West Indian values: Some relevant data from Trinidad and Tobago. British Journal of Sociology, 8, 109-116.

Papajohn, J. C., \& Spiegel, J. P. (1975). Transactions in families. San Francisco, CA: Jossey-Bass.

Pedersen, P. (1988). A handbook for developing multicultural awareness. Alexandria, VA: American Counseling Association.

Pedhazur, E. J. (1984). Multiple regression in behavior research: Explanation and prediction (2nd ed.). New York: Holt, Rinehart and Winston.

Sodowsky, G. R., Maguire, K., Johnson, P., Ngumba, E., \& Kohles, R. (in press). World view of White American, Mainland Chinese, Taiwanese, and African students: Comparison and counseling implications. Journal of Cross-Cultural Psychology.

Sue, D. W. (1978a). World view and counseling. The Personnel and Guidance Journal, 56, 458-462.

Sue, D. W. (1978b). Eliminating cultural oppression in counseling: Toward a general theory. Journal of Counseling Psychology, 25, 419-428.

Sue, D. W., \& Sue, D. (1990). Dimension of world views. In Counseling the culturally different (pp. 137-158). New York: Wiley.

Trimble, J. E. (1976). Value differences among American Indians: Concerns for the concerned counselors. In P. Pederson, W. J. Lonner, \& J. G. Draguns (Eds.), Counseling across cultures (pp. 65-81). Honolulu: The University Press of Hawaii. 